\title{
HESPERALOE FUNIFERA AS A RAW MATERIAL FOR INTEGRAL UTILIZATION OF ITS COMPONENTS
}

\author{
Rafael Sánchez, ${ }^{\mathrm{a}}$ Ana Ferrer, ${ }^{\mathrm{a}}$ Luis Serrano, ${ }^{\mathrm{b}}$ Ana Toledano, ${ }^{\mathrm{b}}$ Jalel Labidi, ${ }^{\mathrm{b}}$ and Alejandro \\ Rodríguez $^{\mathrm{a}, *}$
}

\begin{abstract}
Hesperaloe funifera was characterized in terms of its contents of holocellulose, $\alpha$-cellulose, and lignin (74.1, 52.3, and $7.9 \%$, respectively).

Also, an experimental factor design was used to examine the influence of operational variables in the diethanolamine pulping of this material (viz. diethanolamine concentration (50-80\%), cooking temperature (155-185 ${ }^{\circ} \mathrm{C}$ ), and time (30-90 minutes)) on the contents of holocellulose, $\alpha$ cellulose, and lignin, as well as the yield, kappa number, and viscosity of the resulting pulps, and also on the brightness, tensile index, stretch, burst index, and tear index of paper sheets made from it. The predictions for these dependent variables departed by less than $1,7,6,2,2,4,15$, $11,12,10$, and $37 \%$ from their respective experimental values. Black liquors obtained from the pulping runs were characterized by determining $\mathrm{pH}$, density, TDS, (total dissolved solids), MI (inorganic matter), MO (organic matter), and lignin content; lignin samples were characterized by different techniques (FTIR and TGA). Finally, the black liquors were acidified to separate solid fractions that were subjected to pyrolysis and gasification in order to obtain synthesis and fuel gases.
\end{abstract}

Keywords: Hesperaloe funifera; Pyrolysis; Paper; Fuel gases; Lignin; Neural fuzzy model

Contact information: a: Chemical Engineering Department, Campus of Rabanales, 14071, University of Córdoba, Córdoba, Spain; b: "Materials + Technology" Group, Chemical and Environmental Engineering Department, University of the Basque Country, Spain; * Corresponding author: Alejandro Rodriguez, e-mail: a.rodriguez@uco.es

\section{INTRODUCTION}

The forest biorefinery is an evolving vision of wood utilization in an environmentally sustainable and economically viable manner to produce biopower, biofuels, and biomaterials, including paper (Ragauskas 2006). The pulp and paper industry is at the forefront of the forest biorefinery concept. Presently, the existing pulp and paper manufacturing facilities are almost exclusively involved with the production of pulp and paper. However, it is possible to integrate other processes, enabling competitive advantages (Ragauskas 2006; van Heiningen 2006).

Paper production from delignified cellulosic fibers has increased by $4.3 \%$ over the period from 2000 to 2007 (FAO) as a result of the development of a number of new uses, including the manufacture of specialty paper products (e.g., filter, chromatographic, electrotechnical, tissue paper, bag paper, multilayer bags, food packaging, and paper composites) (ASPAPEL). The rise has been especially rapid in recent years, with the growing production of cellulose pulp from non-wood fiber obtained from agricultural and agrifood residues, as well as unconventional plant materials rather than wood fiber. Thus, 
pulp production from non-wood raw materials in the previous period increased by $18.1 \%$ versus only $3.1 \%$ for wood materials; however, the amount of cellulose obtained from wood sources materials in 2007 continued to greatly exceed the figure for non-wood materials (177 million ton versus only 18.3 million ton) (FAO).

Some alternative, unconventional plant raw materials have potential to provide large amounts of biomass for producing quality cellulose pulp. One such source of raw material is Hesperaloe funifera plants, which grow with little water requirements, and which have a fibre morphology that is especially suitable for making pulp for paper. Hesperaloe funifera is a shrubby plant of the family Agavaceae that is up to $80 \mathrm{~cm}$ tall and 1.0 to $1.2 \mathrm{~m}$ wide with long leaves up to $5 \mathrm{~cm}$ wide and 2 to $3 \mathrm{~cm}$ thick. All species in its genus originated in Mexico and its neighbouring USA regions, where it is used mainly for ornamental purposes (Guillot and Van der Meer 2006).

Although the fibre morphology of Hesperaloe funifera plants has been previously mentioned (McLaughlin 2000), little research in this direction appears to have been conducted. In the few exceptions, the material was subjected to alkaline sulphiteanthraquinone or soda-anthraquinone pulping (Wong and McLaughlin 1999, 2000; Fairbank and Detrick 2000), and the resulting paper sheets were found to have very high tensile, burst, and tear indices, which implies high potential for used in specialty paper products.

Solvents have had a long history in pulping (López et al., 2006; Rodríguez and Jiménez, 2008), where they have a dual purpose: By delignifying the raw material, they provide individual fibers, without the use of sulfur compounds, and lignin can be recovered from the pulping waste liquor after removal of the solvent, which is recycled to the cooking process. Particularly interesting are the pulping with solvents of high boiling point (glycols and amines) (Rodríguez and Jiménez 2008); such processes would be able to use the classic conventional facilities such as the kraft process, which operate at moderate pressures.

Several processes have been used to extract lignin or/and to produce pulp and paper from lignocellulosic materials. As a consequence of the pulping process, lignin is dissolved from the raw material, being separated in the form of black or brown liquor rich in phenolic compounds (Fengel and Wegener 1989). The pulp and paper industries normally burn the lignin dissolved in the black liquor for energy generation. According to International Lignin Institute (ILI), the pulp and paper industry produces between 40 and 50 million tons per year of lignin, and only about $1.5 \%$ is commercialized with specific applications. The lignin can be isolated and used as a starting material for useful products (Gargulak et al. 2000).

Lignin is a natural amorphous polymer that acts as the essential glue that gives plants their structural integrity. It is a main constituent of lignocellulosic biomass (15$30 \%$ by weight) (Perlack et al. 2005), together with cellulose and hemicelluloses; however, lignin has received little attention relative to cellulose with regards to its valorisation. With its unique structure and chemical properties, a wide variety of bulk and fine chemicals, particularly aromatic compounds, as well as fuels are potentially obtainable from lignin.

Lignin can be used as polyols for various applications such as the synthesis of polyurethane and phenol-formaldehyde resins (Lora and Glasser 2002; Park et al. 2008; 
Cateto et al. 2008a, 2008b). Lignin can also be used for the production of bioproducts such as vanillin, guaiacol, and other phenolic compounds (Bunarov and Mazza 2008). One special use of lignin is for the production of chemical intermediates for synthesis, which can be obtained by pyrolysis (Baumlin et al. 2006; Mani et al. 2009; Murugan et al. 2008) or fuel gases by gasification (Osada et al. 2007; Furusawa et al. 2007; Yamaguchi et al. 2008, 2009).

In this work, Hesperaloe funifera was characterized in terms of its contents in holocellulose, $\alpha$-cellulose, and lignin. Also, it is used an experimental factor design to examine the influence of operational variables in the diethanolamine pulping of this material (viz. diethanolamine concentration, cooking temperature, and time) on the contents in holocellulose, $\alpha$-cellulose, lignin, yield, viscosity, and kappa number of the resulting pulps, and also on the breaking length, stretch, burst index, tear index, and brightness of paper sheets made from it. Black liquors pulping were characterized by determining $\mathrm{pH}$, density, TDS, MI, MO, and lignin content; lignin samples were characterized by different techniques (FTIR and TGA). Finally, the black liquors were acidified to separate solid fractions that were subjected to pyrolysis and gasification in order to obtain synthesis and fuel gases.

\section{EXPERIMENTAL}

\section{Characterization of Hesperaloe funifera}

Samples of Hesperaloe funifera fibre for educational and research purposes were kindly supplied by the Hesperaloe Project research team at the University of Arizona. Following drying at room temperature, the raw material was cold ground in a Retsch SM 2000 mill to avoid alterations in its components. The raw materials quantity that will be used is subsequently saved in plastic bags before cooking processes. Lignin, $\alpha$-cellulose, and holocellulose were determined using the following standard methods: TAPPI T-222, TAPPI T-203 0S-61, and the method of Wise (Wise et al. 1946), respectively.

\section{Pulping}

The three operational variables that were used during diethanolamine cooking of Hesperaloe funifera were: temperature $\left(155,170\right.$, and $\left.185^{\circ} \mathrm{C}\right)$, time $(30,60$, and 90 minutes), diethanolamine concentration (50, 65, and $80 \%$ o.d), with a constant liquid/solid ratio of 8 (Rodríguez et al. 2008a, 2008b; Jiménez et al. 2008).

The raw material was introduced in a $15 \mathrm{~L}$ batch reactor that was heated by an outer jacket containing electrical wires, with diethanolamine as solvent, fitting the total volume considering the liquid/solid ratio elected. The reactor contents were stirred by rotating the reaction vessel via a motor connected through a rotary axle to a control unit including the required instruments for measurement and control of pressure and temperature. Once the temperature of reaction was reached (at a heating rate of $10{ }^{\circ} \mathrm{C} /$ min), the temperature was maintained during the specified time, and then the cooked material, separated from the black liquor by a filter, was washed with water at room temperature to remove residual cooking liquor and fiberized in a disintegrator at 1200 rpm for $30 \mathrm{~min}$ at room temperature and with a consistency of $10 \%$. Pulp was beaten in a 
Sprout-Bauer refiner operating at $0.5 \%$ pulp consistency, using a disk spacing of $0.1 \mathrm{~mm}$, and the fiberized material was passed through a Sommerville screen model K134 to remove uncooked particles, while water was eliminated through centrifugation.

\section{Characterization of Pulps and Paper Sheets}

As in the chemical characterization of raw material, pulps obtained were analyzed according to common standards, determining its content in lignin, $\alpha$-cellulose, and holocellulose.

The viscosity and kappa number of the pulp were determined according to TAPPI standards T-230 and T-236, and beating degree according to ISO 5267/1. Pulp yield was determined by weighing.

Paper sheets with a grammage of $60 \mathrm{~g} / \mathrm{m}^{2}$ were obtained by using an Enjo-F39.71 sheet former according to UNE 57-042. Followed conditioning in accordance with UNE 57-001, the sheets were characterized in terms of tensile index (T-494), stretch (T-404), burst index (T-403), tear index (T-414), and brightness (T-525).

\section{Experimental Design}

The experimental factorial design used consisted of a series of points (tests) around a central composition point (central test) that were used to estimate the constants or parameters of a neural fuzzy model. The design met the general requirement that it allowed all parameters in the mathematical model to be estimated with a relatively small number of tests, (Montgomery 1991).

The relationships between the dependent variables (viz. holocellulose, $\alpha$-cellulose, lignin, pulp yield, Kappa number, viscosity, tensile index, burst index, tear index, and brightness) and the independent (operational) variables were established by using a neural fuzzy model. This type of model combines the advantages of fuzzy logic systems (Zadeh 1965) and neural networks (Works 1989), and provides a powerful prediction tool based on the following equation (Jang 1993) with three independent variables, the use of a Singleton defuzzifier (a constant parameter) and a linear membership function for the independent variables,

$$
Y_{e}=\frac{\sum_{l=1}^{8} c_{l}\left[\prod_{i=1}^{4} \begin{array}{c}
2 \\
\prod_{j=1}
\end{array}\right]}{\sum_{l=1}^{8}\left[\prod_{i=1}^{4} X_{i j}^{2}\right.}
$$

where $Y_{e}$ is the estimated value of the property to be modelled and $c_{l}$ is the defuzzifier of a fuzzy rule; $x_{i}$ denotes the values of temperature $(T)$, time $(t)$, and diethanolamine concentration $(D)$, and $\mathrm{j}$ being 1 or 2 in the following equation: 


$$
x_{i 1}=1-\frac{1}{\left(x_{\text {high }}-x_{\text {low }}\right)}\left(x-x_{\text {low }}\right) \quad x_{i 2}=\frac{1}{\left(x_{\text {high }}-x_{\text {low }}\right)}\left(x-x_{\text {low }}\right)
$$

with $x_{\text {high }}$ and $x_{\text {low }}$ being the extreme values of each variable.

With three independent variables, one can establish the following 8 fuzzy rules $\left(\mathrm{R}_{\mathrm{i}}\right)$ based on the extreme (high and low) values of such variables:

$$
\begin{aligned}
& \mathrm{R}_{1} \text { : low } T \text {, low } t \text {, and low } D \\
& \mathrm{R}_{2} \text { : low } T \text {, low } t \text {, and high } D \\
& \mathrm{R}_{7} \text { : high } T \text {, high } t \text {, and low } D \\
& \mathrm{R}_{8} \text { : high } T \text {, high } t \text {, and high } \mathrm{D}
\end{aligned}
$$

With a Gaussian membership function with three levels (low, medium, and high) for one of the variables and a linear membership function with two levels (low and high) for the other two, Eq. 1 would contain 12 terms in the numerator and another 12 in the denominator. The Gaussian membership function would be of the form,

$$
x_{i}=\exp \left(-0.5\left(\frac{x-x_{c}}{L}\right)^{2}\right)
$$

where $x$ is the absolute value of the variable concerned, $x_{c}$ is its minimum, central or maximum value, and $L$ is the width of its Gaussian distribution.

The parameters and constants in the previous equation were estimated by using the ANFIS $\odot$ (Adaptive Neural Fuzzy Inference System) Edit tool in the Matlab v. 6.5 software suite.

\section{Black Liquors Characterization}

The main physico-chemical properties of obtained black liquor were determined according to standard methods. The $\mathrm{pH}$ was measured with a digital SELECTA $\mathrm{pH}$-meter "pH-2005". Density was determined measuring the weight of the black liquor in a known volume that was previously weighed and moisture-free. Total dissolved solids (TDS) were measured after keeping a weighed sample at $100^{\circ} \mathrm{C}$ until constant weight. Inorganic matter was determined after combustion of the sample at $525^{\circ} \mathrm{C}$ (TAPPI T211 om-93). Organic matter was defined as the difference between total dissolved solids and inorganic matter. Lignin content was balance weighted after precipitation from the liquid fraction (see next section).

\section{Characterization of Lignin Removed from the Black Liquors}

To precipitate the lignin from diethanolamine liquors, two volumes of acidified water at $\mathrm{pH} 2$ were added (González et al. 2009), after which the liquor was centrifuged and the obtained solid was recovered, washed with acidified water at $\mathrm{pH} 2$ to remove impurities, and then vacuum dried at $50{ }^{\circ} \mathrm{C}$ until constant weight. 
Finally, lignin samples were characterized by different techniques (FTIR and TGA). Lignins were characterized by attenuated-total-reflection infrared (ATR-IR) spectroscopy by direct transmittance in a single reflection ATR system (ATR top plate fixed to an optical beam condensing unit with a ZnSe lens) with an MKII Golden Gate SPECAC instrument. Each spectrum was recorded over 20 scans in the range from 4000 to $600 \mathrm{~cm}^{-1}$ with a resolution of $2 \mathrm{~cm}^{-1}$.

The thermal stability of the lignins was studied in terms of thermogravimetric analysis (TGA). A dynamic scan from 25 to $800{ }^{\circ} \mathrm{C}$ at $10{ }^{\circ} \mathrm{C} / \mathrm{min}$ was done under nitrogen atmosphere employing a TGA-92 thermobalance from Setaram.

\section{Synthesis and Fuel Gases from Black Liquors}

The liquor from pulping process was treated with sulphuric acid at $\mathrm{pH} 6,4$, and 2 to obtain various solid fractions, which were then dried at room temperature and subjected to pyrolysis in a helium atmosphere and gasification with a 9:1 mixture of helium and oxygen. The experimental system (Conesa et al., 2009) consisted of a quartz tube, $10 \mathrm{~mm}$ wide, where the sample is introduced uniformly occupying an appreciable length of the tube (approx. 350-400 mm). A horizontal actuator (servomechanism that supplies and transmits a measured amount of energy for the operation of another mechanism or system) introduces the tube with lignocellulosic material inside a furnace maintained at the desired temperature $\left(850{ }^{\circ} \mathrm{C}\right)$ with a constant linear velocity. The operating conditions used for gasification were selected among those commonly used for similar lignocel-lulosic material experiments. The gases obtained in the gasification and pyrolisis processes were analyzed by GC-TCD (Shimadzu GC-14A Gas Chromatograph) and GC-FID (Shimadzu GC-17A).

\section{RESULTS AND DISCUSSION}

\section{Characterization of Hesperaloe funifera}

The contents in holocellulose, lignin, $\alpha$-cellulose, of the raw material Hesperaloe funifera were found to be $74.1 \%, 7.9 \%$, and $52.3 \%$, respectively. All the experiments were triplicated. It was possible to obtain pulps with good values of kappa number and brightness due to the low lignin content. The hemicellulose / $\alpha$-cellulose ratio $(1 / 2)$ is suitable for the production of cellulose pulp and paper, to promote the swelling of the fiber and increase its plasticity, flexibility, and bonding ability, thus improving the density and the strength properties of the sheet (García Hortal 2007; Cordeiro et al. 2004). However, considering that the hemicellulose content is important in the physical properties of paper sheets, in the case of Hesperaloe, its low hemicellulose content might require more energy to get good values of tensile index (García Hortal 2007).

\section{Neural Fuzzy Model for Pulping}

Table 1 shows the experimental values of the pulps and paper sheets properties, which differed by less than 5\% from their means as obtained in triplicate measures.

The experimental data of Table 1 were processed with the ANFIS Edit tool in MATLAB 6.5 to estimate the parameters or constants in the equation for the neural fuzzy 
model established with linear membership functions at two different levels (high and low) for two operational variables and a Gaussian membership function at three levels (high, medium, and low) for the other.

Table 2 shows the parameter values $\left(c_{i}\right)$ for the equations of the neural fuzzy model based on Gaussian membership functions at three levels of time and linear functions at two levels of temperature and the diethanolamine concentration for holocellulose, $\alpha$-cellulose, yield, viscosity, Kappa number, stretch and burst index. The table also shows the constants for lignin content and brightness as calculated with a Gaussian function for the diethanolamine concentration and linear functions for the other two, as well as those for tensile index and tear index as calculated with a Gaussian function for temperature and a linear function for time and the diethanolamine concentration.

Table 3 shows the estimated values of the dependent variables provided by the neural fuzzy models. As can be seen, the predictions for holocellulose, $\alpha$-cellulose, lignin, yield, kappa number, viscosity, brightness, tensile index, stretch, burst index, and tear index departed by less than $1,7,6,2,2,4,15,11,12,10$, and $37 \%$ from their respective experimental counterparts. The large error made in predicting the tear index makes the neural fuzzy model unsuitable for this paper property.

The neural fuzzy models were validated by conducting three pulping experiments. Table 3 (In the last three rows) shows the operating conditions used, the properties of the resulting pulp and paper, and the percent differences from the predictions. The high regression coefficients $\left(R^{2}\right)$ obtained testifies to the accuracy of the proposed models. In fact, the corresponding equations provide quite accurate predictions as a function of the operating conditions used. A neural fuzzy model affords physical interpretation of the constants (parameters) inasmuch as these represent the mean values of the target properties (dependent variables) under the conditions defined by the specific fuzzy rule used. For example, using low levels of temperature, time, and the diethanolamine concentration is predicted to lead to a yield of $57.5 \%$ (rule 1 in Table 2), which coincides with the value of the corresponding parameter in the equation.

Also, neural fuzzy models allow the influence of each operational variable on the target properties to be assessed. This can be easily illustrated with the results for yield. The parameter values of the model for estimating this property are shown in Table 2. As can be seen, the highest yields were obtained at low levels of temperature, time and diethanolamine concentration; on the other hand, the lowest yields were obtained at high levels of the three independent variables.

Applying rules 1 and 2 in Table 2 reveals that, with low levels of the operational variables (rule 1), increasing the diethanolamine concentration (rule 2) decreases yield (from 57.5 to $52.7 \%$ ). Likewise, a comparison of rules 1 and 3 reveals that, at low temperature and concentration levels, increasing the pulping time decreases yield from 57.5 to $52.5 \%$ on average. Finally, increasing the temperature (rules 1 and 7 ) decreases pulp yield from $57.5 \%$ to $52.5 \%$. On the other hand, comparing rule 8 with 12 , it is observed that yield varies very little (49.3 to $49.0 \%$ ) by varying the time from the lowest value (30 minutes) to the highest value (90 minutes). Using a similar analysis for the other rules could be concluded that temperature is the most influential independent variable while the independent variable time is the least influential (Fig 1-3). 
Table 1. Experimental Values of the Pulp and Paper Sheet Properties Obtained by Diethanolemine Pulping of Hesperaloe funifera (deviations in brackets)

\begin{tabular}{|c|c|c|c|c|c|c|c|c|c|c|c|}
\hline $\begin{array}{l}\text { Operation Conditions } \\
\text { Temperature }\left({ }^{\circ} \mathrm{C}\right) \text {, time }(\mathrm{min}) \text { and } \\
\text { diethanolamine concentration }(\%)\end{array}$ & $\begin{array}{c}\text { Holocellulose, } \\
\%\end{array}$ & $\begin{array}{c}\text { a-cellulose, } \\
\%\end{array}$ & $\begin{array}{l}\text { Lignin, } \\
\%\end{array}$ & $\begin{array}{c}\text { Yield, } \\
\%\end{array}$ & $\begin{array}{l}\text { Kappa } \\
\text { number }\end{array}$ & $\begin{array}{l}\text { Viscosity, } \\
\mathrm{mL} / \mathrm{g}\end{array}$ & $\begin{array}{c}\text { Brightness, } \\
\% \text { ISO }\end{array}$ & $\begin{array}{c}\text { Tensile } \\
\text { index, } \\
\mathrm{Nm} / \mathrm{g}\end{array}$ & $\begin{array}{c}\text { Stretch, } \\
\%\end{array}$ & $\begin{array}{c}\text { Burst } \\
\text { index, } \\
k N / g\end{array}$ & $\begin{array}{c}\text { Tear } \\
\text { index, } \\
\mathrm{mNm}^{2} / \mathrm{g}\end{array}$ \\
\hline $170,60,65$ & $90.7(0.9)$ & $73.0(2.0)$ & $9.13(0.91)$ & $51.2(3.0)$ & $21.5(0.1)$ & 729 (32) & $28.7(0.7)$ & $75.4(6.9)$ & $3.07(0.51)$ & $6.04(0.27)$ & $3.69(0.45)$ \\
\hline $185,90,80$ & $93.0(1.1)$ & 75.5 (1.1) & $8.40(1.40)$ & $49.4(2.9)$ & $20.3(0.7)$ & $686(15)$ & $37.8(1.0)$ & $53.4(2.2)$ & $4.09(0.33)$ & $4.94(0.15)$ & $5.74(0.39)$ \\
\hline $155,90,80$ & $91.4(1.2)$ & $74.1(1.5)$ & $8.78(0.34)$ & $50.6(1.8)$ & $20.5(1.9)$ & $715(24)$ & $33.7(0.7)$ & $68.1(3.9)$ & $3.01(0.43)$ & $5.88(0.28)$ & $2.71(0.64)$ \\
\hline $185,90,50$ & $91.5(1.2)$ & $74.8(0.9)$ & $8.49(1.47)$ & $50.1(1.4)$ & $20.4(0.5)$ & $691(26)$ & $36.4(1.1)$ & $48.8(3.3)$ & $4.39(0.31)$ & $4.84(0.19)$ & $6.29(0.52)$ \\
\hline $155,90,50$ & $88.8(1.2)$ & $56.6(1.1)$ & $9.84(1.11)$ & $57.6(4.5)$ & $23.1(0.1)$ & $781(28)$ & $32.0(0.8)$ & $77.1(2.6)$ & $3.27(0.22)$ & $6.43(0.40)$ & $3.07(0.34)$ \\
\hline $185,30,80$ & $91.6(0.8)$ & $75.0(0.4)$ & $8.64(1.21)$ & $49.8(2.3)$ & $20.3(0.4)$ & $688(17)$ & $34.6(0.9)$ & $69.4(3.6)$ & $3.85(0.31)$ & $6.04(0.28)$ & $5.87(0.90)$ \\
\hline $155,30,80$ & $90.0(0.4)$ & $63.0(2.1)$ & $9.81(0.85)$ & $53.1(3.6)$ & $22.6(0.1)$ & $765(46)$ & $31.9(0.6)$ & $82.7(6.5)$ & $2.90(0.27)$ & $6.99(0.48)$ & $2.83(0.32)$ \\
\hline $185,30,50$ & $90.3(0.6)$ & $66.3(1.9)$ & $9.42(0.34)$ & $52.9(3.1)$ & $22.2(0.1)$ & $752(37)$ & $32.6(0.8)$ & $65.1(4.7)$ & $3.88(0.20)$ & $5.92(0.17)$ & $6.73(0.48)$ \\
\hline $155,30,50$ & $88.7(0.3)$ & $56.2(1.7)$ & $9.87(0.60)$ & $57.7(2.7)$ & $23.7(0.4)$ & $860(61)$ & $26.9(0.7)$ & $87.1(5.7)$ & $3.16(0.19)$ & $7.59(0.45)$ & $2.93(0.34)$ \\
\hline $170,90,65$ & $90.8(0.5)$ & $73.1(2.5)$ & $9.12(1.21)$ & $51.2(1.5)$ & $21.2(0.1)$ & $726(21)$ & $30.0(0.9)$ & $68.1(3.2)$ & $3.71(0.30)$ & $6.01(0.26)$ & $4.83(0.15)$ \\
\hline $170,30,65$ & $90.6(0.4)$ & $71.2(2.1)$ & $9.13(1.41)$ & $52.2(0.9)$ & $22.1(0.3)$ & $731(47)$ & $27.5(0.7)$ & $83.7(5.4)$ & $3.47(0.19)$ & $6.99(0.24)$ & $4.08(0.26)$ \\
\hline $170,60,80$ & $91.1(1.1)$ & $73.5(1.4)$ & $8.98(1.32)$ & $50.8(1.4)$ & $20.9(0.3)$ & $723(51)$ & $29.0(0.7)$ & $69.8(4.6)$ & $3.23(0.34)$ & $6.46(0.28)$ & $3.54(0.47)$ \\
\hline $170,60,50$ & $90.4(1.7)$ & 70.7 (1.9) & $9.16(0.23)$ & $52.3(4.2)$ & $22.1(0.9)$ & $733(55)$ & $28.9(0.7)$ & $65.7(6.6)$ & $3.08(0.39)$ & $5.63(0.56)$ & $3.14(0.48)$ \\
\hline $185,60,65$ & $91.3(0.5)$ & $73.6(2.4)$ & $8.81(0.84)$ & $50.7(5.2)$ & $20.8(0.2)$ & $721(33)$ & $30.4(1.0)$ & $52.0(3.7)$ & $3.89(0.28)$ & $4.51(0.11)$ & $7.05(0.44)$ \\
\hline $155,60,65$ & $90.4(0.3)$ & $70.6(2.7)$ & $9.35(0.49)$ & $52.3(6.7)$ & $22.1(0.2)$ & $744(64)$ & $27.0(0.6)$ & $72.3(5.9)$ & $2.92(0.85)$ & $6.48(0.23)$ & $5.05(0.87)$ \\
\hline $162.5,45,61$ & $90.4(0.8)$ & $66.8(1.8)$ & $8.85(0.78)$ & $52.7(7.3)$ & $21.4(0.3)$ & $761(12)$ & $25.9(0.4)$ & $76.3(4.3)$ & $3.11(0.43)$ & $6.79(0.21)$ & $3.22(0.75)$ \\
\hline $173,67,70$ & $90.1(0.9)$ & $73.0(0.8)$ & $8.69(0.65)$ & $50.8(2.5)$ & $20.4(0.8)$ & 717 (48) & $30.2(0.8)$ & $67.8(6.1)$ & $3.42(0.57)$ & $5.77(0.18)$ & $4.12(0.45)$ \\
\hline $181,83,78$ & $90.8(1.0)$ & $75.2(0.4)$ & $8.17(1.01)$ & $48.4(4.9)$ & $20.1(0.6)$ & $666(31)$ & $35.3(0.9)$ & $46.5(2.3)$ & $3.75(0.36)$ & $5.32(0.31)$ & $5.58(0.63)$ \\
\hline
\end{tabular}


Table 2. Values of the Constants $c_{i}$ in the Neural Fuzzy Model for the Pulp and Paper Sheets Properties and the $R^{2}$ Value

\begin{tabular}{|c|c|c|c|c|c|c|c|c|c|c|c|c|c|c|}
\hline \multirow[b]{2}{*}{ Rule } & \multicolumn{3}{|c|}{ Operational variables } & \multicolumn{7}{|c|}{ Dependent variables } & \multirow[b]{2}{*}{$\begin{array}{l}\text { Tensile } \\
\text { index, } \\
\mathrm{Nm} / \mathrm{g}\end{array}$} & \multirow[b]{2}{*}{$\begin{array}{l}\text { Stretch, } \\
\%\end{array}$} & \multirow[b]{2}{*}{$\begin{array}{l}\text { Burst } \\
\text { index, } \\
\mathrm{kN} / \mathrm{g}\end{array}$} & \multirow[b]{2}{*}{$\begin{array}{l}\text { Tear } \\
\text { index, } \\
\mathrm{mNm}^{2} / \mathrm{g}\end{array}$} \\
\hline & $\mathrm{T},{ }^{\circ} \mathrm{C}$ & $\mathrm{T}, \min$ & $\mathrm{D}, \%$ & $\begin{array}{l}\text { Holocellulose, } \\
\%\end{array}$ & $\begin{array}{l}\alpha \text {-cellulose, } \\
\%\end{array}$ & $\begin{array}{l}\text { Lignin, } \\
\%\end{array}$ & $\begin{array}{l}\text { Yield, } \\
\%\end{array}$ & $\begin{array}{l}\text { Kappa } \\
\text { number }\end{array}$ & $\begin{array}{l}\text { Viscosity, } \\
\mathrm{mL} / \mathrm{g}\end{array}$ & $\begin{array}{l}\text { Brightness, } \\
\% I S O\end{array}$ & & & & \\
\hline 1 & $155(-1)$ & $30(-1)$ & $50(-1)$ & 88.9 & 56.8 & 9.65 & 57.5 & 23.5 & 858 & 26.2 & 86.5 & 3.93 & 7.89 & 3.24 \\
\hline 2 & $155(-1)$ & $30(-1)$ & $80(1)$ & 90.3 & 63.8 & 9.66 & 52.7 & 22.4 & 758 & 30.9 & 81.5 & 3.11 & 7.20 & 3.11 \\
\hline 3 & $155(-1)$ & $60(0)$ & $50(-1)$ & 90.3 & 70.7 & & 52.5 & 22.5 & 738 & & & 2.81 & 6.50 & \\
\hline 4 & $155(-1)$ & $60(0)$ & $80(1)$ & 90.9 & 73.3 & & 51.0 & 21.3 & 731 & & & 3.01 & 7.42 & \\
\hline 5 & $155(-1)$ & $90(1)$ & $50(-1)$ & 88.8 & 56.5 & 9.62 & 57.4 & 23.0 & 783 & 31.5 & 76.9 & 3.51 & 6.68 & 3.37 \\
\hline 6 & $155(-1)$ & $90(1)$ & $80(1)$ & 91.5 & 75.0 & 8.57 & 50.2 & 20.3 & 714 & 32.7 & 66.9 & 3.22 & 6.04 & 2.88 \\
\hline 7 & $185(1)$ & $30(-1)$ & $50(-1)$ & 90.5 & 67.4 & 9.21 & 52.5 & 22.0 & 745 & 32.0 & 62.8 & 4.10 & 6.25 & 7.10 \\
\hline 8 & $185(1)$ & $30(-1)$ & $80(1)$ & 91.9 & 76.5 & 8.46 & 49.3 & 20.1 & 677 & 33.6 & 67.1 & 4.05 & 6.31 & 6.01 \\
\hline 9 & $185(1)$ & $60(0)$ & $50(-1)$ & 91.2 & 73.2 & & 51.0 & 21.1 & 719 & & & 3.78 & 4.39 & \\
\hline 10 & $185(1)$ & $60(0)$ & $80(1)$ & 91.7 & 74.8 & & 50.0 & 20.1 & 718 & & & 3.98 & 5.41 & \\
\hline 11 & $185(1)$ & $90(1)$ & $50(-1)$ & 91.6 & 75.8 & 8.22 & 49.7 & 20.1 & 688 & 35.8 & 46.6 & 4.64 & 5.12 & 6.48 \\
\hline 12 & $185(1)$ & $90(1)$ & $80(1)$ & 93.3 & 76.4 & 8.20 & 49.0 & 20.1 & 684 & 36.8 & 51.2 & 4.31 & 5.17 & 5.81 \\
\hline 13 & $155(-1)$ & $30(-1)$ & $65(0)$ & & & 8.12 & & & & 25.2 & & & & \\
\hline 14 & $155(-1)$ & $90(1)$ & $65(0)$ & & & 9.19 & & & & 27.5 & & & & \\
\hline 15 & $185(1)$ & $30(-1)$ & $65(0)$ & & & 8.63 & & & & 28.5 & & & & \\
\hline 16 & $185(1)$ & $90(1)$ & $65(0)$ & & & 8.68 & & & & 30.8 & & & & \\
\hline 17 & $170(0)$ & $30(-1)$ & $50(-1)$ & & & & & & & & 78.8 & & & 2.79 \\
\hline 18 & $170(0)$ & $30(-1)$ & $80(1)$ & & & & & & & & 83.7 & & & 3.37 \\
\hline 19 & $170(0)$ & $90(1)$ & $50(-1)$ & & & & & & & & 63.1 & & & 3.78 \\
\hline 20 & $170(0)$ & $90(1)$ & $80(1)$ & & & & & & & & 67.8 & & & 4.36 \\
\hline $\mathrm{R}^{2}$ & & & & 0.98 & 0.94 & 0.98 & 0.98 & 0.99 & 0.96 & 0.80 & 0.91 & 0.97 & 0.93 & 0.83 \\
\hline
\end{tabular}


Table 3. Values of the Dependent Variables as Estimated with Neural Fuzzy Models and Values of Three Experiments used to Validate the Neural Fuzzy Models (deviations from their experimental counterparts in brackets)

\begin{tabular}{|c|c|c|c|c|c|c|c|c|c|c|c|}
\hline $\begin{array}{l}\text { Operational Conditions } \\
\text { Temperature }\left({ }^{\circ} \mathrm{C}\right) \text {, time } \\
\text { (min) and diethanolamine } \\
\text { concentration }(\%)\end{array}$ & $\begin{array}{l}\text { Holocellulose, } \\
\%\end{array}$ & $\begin{array}{l}\alpha \text {-cellulose, } \\
\%\end{array}$ & $\begin{array}{l}\text { Lignin, } \\
\%\end{array}$ & $\begin{array}{l}\text { Yield, } \\
\%\end{array}$ & $\begin{array}{l}\text { Kappa } \\
\text { Number }\end{array}$ & $\begin{array}{l}\text { Viscosity, } \\
\mathrm{mL} / \mathrm{g}\end{array}$ & $\begin{array}{l}\text { Brightness, } \\
\% \text { ISO }\end{array}$ & $\begin{array}{l}\text { Tensile } \\
\text { index, } \\
\mathrm{Nm} / \mathrm{g}\end{array}$ & $\begin{array}{l}\text { Stretch, } \\
\%\end{array}$ & $\begin{array}{l}\text { Burst } \\
\text { index, } \\
\mathrm{kN} / \mathrm{g}\end{array}$ & $\begin{array}{l}\text { Tear } \\
\text { index, } \\
\mathrm{mNm}^{2} / \mathrm{g}\end{array}$ \\
\hline $170,60,65$ & $91.0(0.30)$ & $72.5(0.70)$ & $9.02(2.35)$ & $51.2(0.08)$ & $21.3(0.87)$ & $728(0.21)$ & $28.5(0.53)$ & $72.4(4.01)$ & $3.43(11.65)$ & $5.91(2.11)$ & $3.68(0.41)$ \\
\hline $185,90,80$ & $93.2(0.16)$ & $76.3(1.01)$ & $8.55(2.56)$ & $49.0(0.77)$ & $20.1(0.95)$ & $686(0.06)$ & $36.5(3.40)$ & $51.5(3.64)$ & $4.33(5.92)$ & $5.17(4.60)$ & $5.81(1.22)$ \\
\hline $155,90,80$ & $91.5(0.16)$ & $74.9(1.03)$ & $8.17(2.68)$ & $50.2(0.75)$ & $20.3(0.93)$ & $715(0.06)$ & $32.4(3.82)$ & $68.3(0.31)$ & $3.25(7.88)$ & $6.19(5.42)$ & $3.03(11.80)$ \\
\hline $185,90,50$ & $91.6(0.16)$ & $75.6(1.03)$ & $9.61(2.07)$ & $49.7(0.74)$ & $20.2(0.94)$ & $690(0.06)$ & $35.5(2.24)$ & $47.5(2.64)$ & $4.59(4.55)$ & $5.08(4.93)$ & $6.32(0.55)$ \\
\hline $155,90,50$ & $88.9(0.17)$ & $57.3(1.33)$ & $9.67(2.05)$ & $57.1(0.82)$ & $22.9(0.86)$ & $780(0.06)$ & $31.2(2.54)$ & $76.0(1.40)$ & $3.47(6.11)$ & $6.67(3.67)$ & $3.39(10.64)$ \\
\hline $185,30,80$ & $91.9(0.34)$ & $76.4(1.87)$ & $8.90(2.47)$ & $49.3(0.92)$ & $20.1(1.09)$ & $679(1.28)$ & $33.3(3.73)$ & $67.5(2.73)$ & $4.05(5.26)$ & $6.24(3.27)$ & $5.99(2.07)$ \\
\hline $155,30,80$ & $90.3(0.34)$ & $64.4(2.21)$ & $8.75(2.50)$ & $52.6(0.92)$ & $22.3(1.00)$ & 756 (1.16) & $30.6(4.04)$ & $82.3(0.55)$ & $3.14(8.01)$ & $7.30(4.35)$ & $3.14(10.84)$ \\
\hline $185,30,50$ & $90.6(0.34)$ & $67.7(2.10)$ & $8.29(2.38)$ & $52.4(0.93)$ & $22.0(1.00)$ & 743 (1.18) & $31.8(2.49)$ & $63.8(1.97)$ & $4.08(5.02)$ & $6.14(3.75)$ & $6.84(1.73)$ \\
\hline $155,30,50$ & $89.0(0.34)$ & $57.6(2.47)$ & $9.22(2.15)$ & $57.2(0.94)$ & $23.5(0.93)$ & $851(1.02)$ & $26.1(3.04)$ & $86.0(1.24)$ & $3.36(6.43)$ & $7.81(2.86)$ & $3.21(9.83)$ \\
\hline $170,90,65$ & $91.3(0.58)$ & $71.0(2.81)$ & $9.36(4.90)$ & $51.5(0.63)$ & $20.9(1.40)$ & $718(1.09)$ & $29.8(0.85)$ & $64.6(5.07)$ & $3.91(5.43)$ & $5.78(3.87)$ & $4.10(15.09)$ \\
\hline $170,30,65$ & $90.5(0.11)$ & $66.5(6.50)$ & $8.68(5.26)$ & $52.9(1.30)$ & $22.0(0.68)$ & 757 (3.53) & $27.3(0.91)$ & $80.2(4.16)$ & $3.66(5.33)$ & $6.87(1.69)$ & $3.25(20.32)$ \\
\hline $170,60,80$ & $91.4(0.28)$ & $73.9(0.56)$ & $8.59(0.54)$ & $50.5(0.60)$ & $20.7(1.17)$ & $723(0.02)$ & $33.2(14.38)$ & $74.2(6.31)$ & $3.49(8.14)$ & $6.27(3.01)$ & $3.87(9.27)$ \\
\hline $170,60,50$ & $90.7(0.29)$ & $71.1(0.57)$ & $9.19(1.67)$ & $52.0(0.60)$ & $21.9(1.20)$ & $733(0.02)$ & $31.2(8.01)$ & $70.6(7.60)$ & $3.36(9.29)$ & $5.56(1.26)$ & $3.48(10.82)$ \\
\hline $185,60,65$ & $91.5(0.19)$ & $74.0(0.47)$ & $9.02(1.23)$ & $50.4(0.51)$ & $20.6(0.80)$ & $716(0.59)$ & $30.2(0.55)$ & $57.6(10.64)$ & $3.91(0.58)$ & $4.92(9.13)$ & $6.24(11.41)$ \\
\hline $155,60,65$ & $90.5(0.20)$ & $71.0(0.48)$ & $9.02(1.22)$ & $52.0(0.50)$ & $21.9(0.84)$ & $740(0.57)$ & $26.8(0.63)$ & $78.2(8.17)$ & $2.94(0.82)$ & $6.90(6.48)$ & $3.19(36.71)$ \\
\hline $162.5,45,61$ & $90.8(0.40)$ & $67.2(0.56)$ & $9.11(2.87)$ & $52.9(0.39)$ & $21.8(1.64)$ & $762(0.14)$ & $27.1(4.60)$ & $77.7(1.83)$ & $3.21(3.03)$ & $6.91(1.68)$ & $3.53(8.81)$ \\
\hline $173,67,70$ & $90.2(0.17)$ & $73.4(0.57)$ & $8.78(1.04)$ & $51.1(0.64)$ & $20.6(1.02)$ & $719(0.31)$ & $32.3(6.49)$ & $68.5(1.08)$ & $3.51(2.59)$ & $6.01(3.94)$ & $4.45(7.50)$ \\
\hline $181,83,78$ & $90.9(0.17)$ & $75.7(0.64)$ & $8.34(2.06)$ & $48.9(1.00)$ & $20.3(0.80)$ & $680(2.12)$ & $35.3(0.89)$ & $51.1(8.92)$ & $3.95(5.11)$ & $5.62(5.25)$ & $6.31(11.61)$ \\
\hline
\end{tabular}




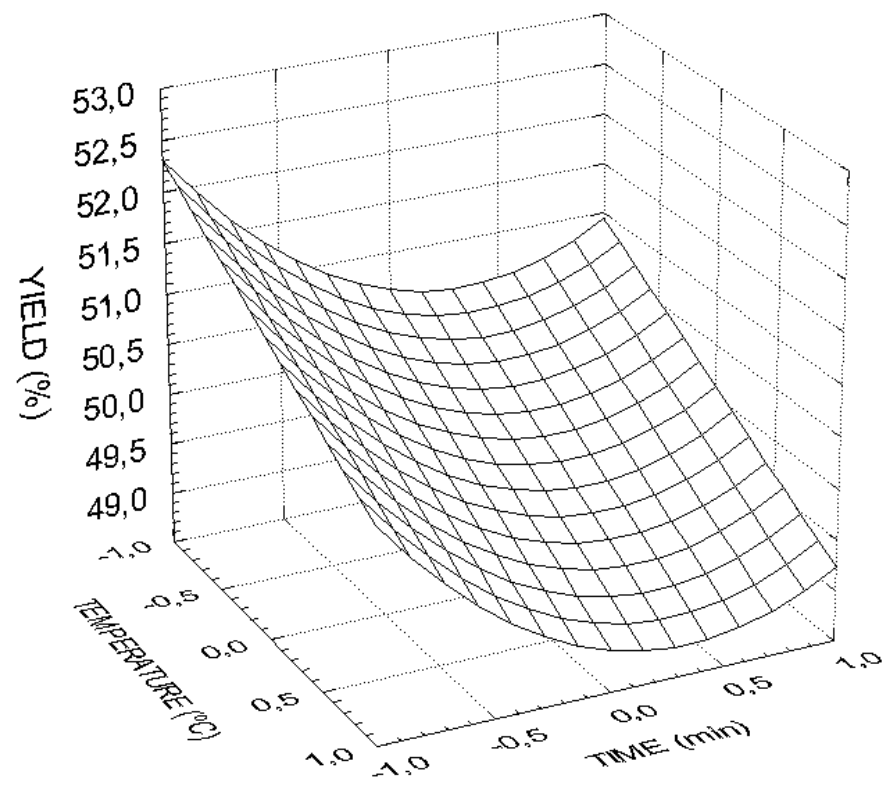

Figure 1. Variation of yield of pulps with the temperature and cooking time at high value of diethanolamine concentration

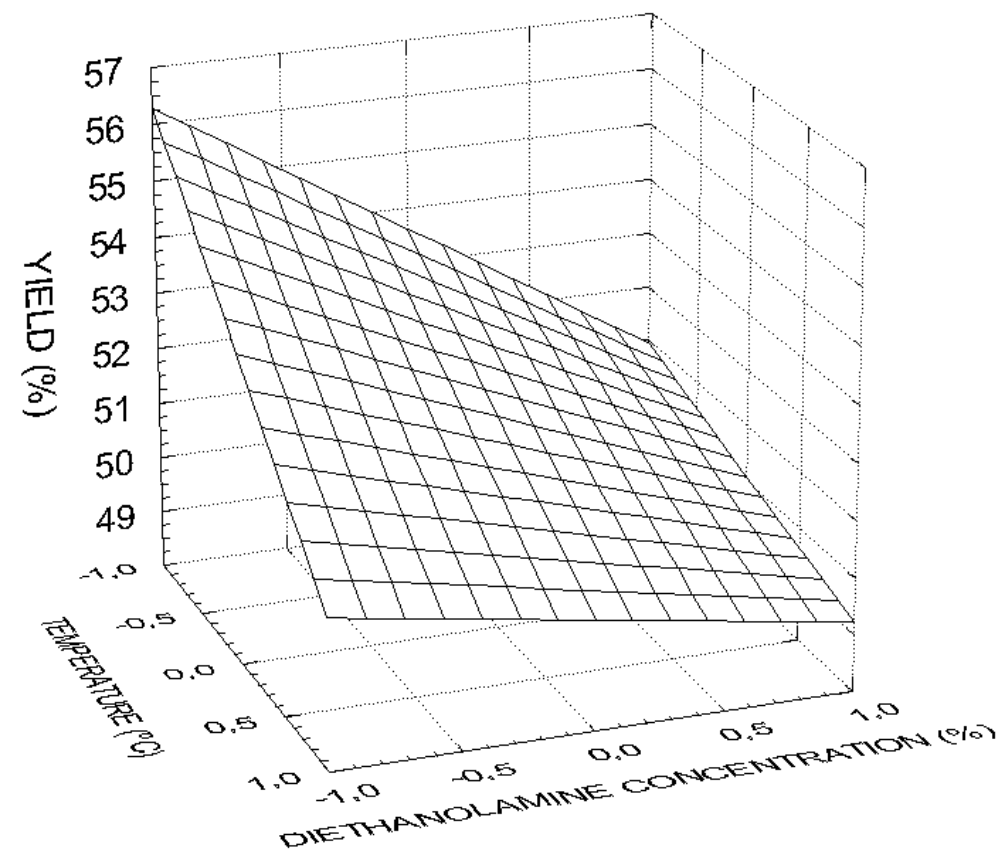

Figure 2. Variation of yield of pulps with the temperature and diethanolamine concentration at high value of cooking time 


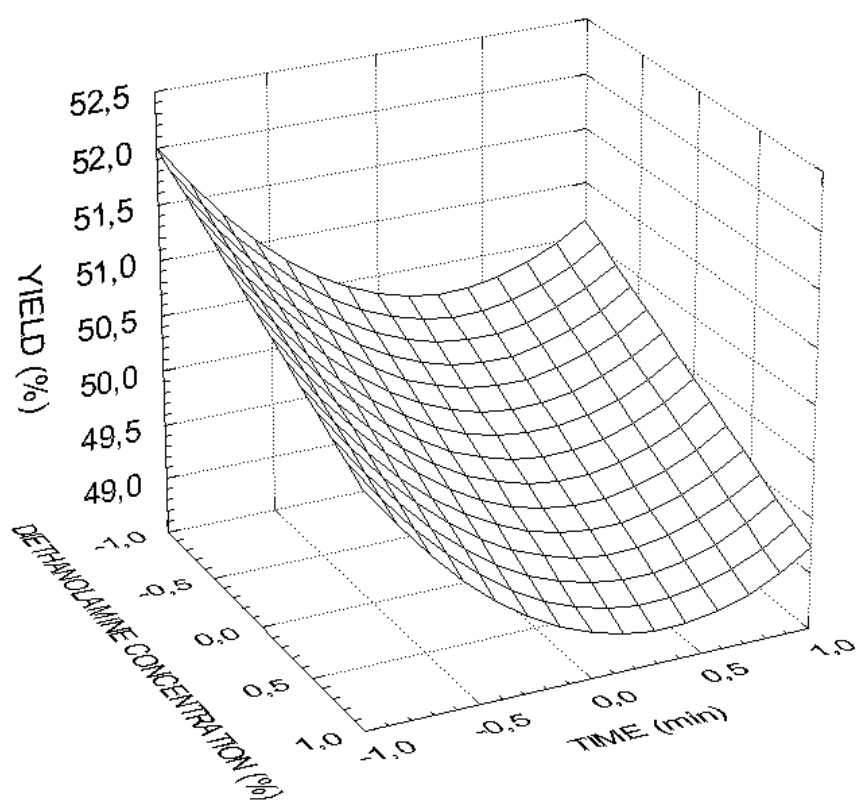

Figure 3. Variation of yield of pulps with the diethanolamine concentration and time at high value of temperature

\section{Characterization of Black Liquors}

As can be seen in Table 4, the temperature did not greatly influence the dry matter (TDS), inorganic, and organic contents in the analyzed samples, even when lignin content was high at the lower reaction temperature (average of $4.46 \cdot 10^{-3}$ to $155{ }^{\circ} \mathrm{C}$ ). The diethanolamine concentration used did not have great influence in the analyzed samples, although at a lower concentration (50\%) the major organic content was obtained in the samples $(9.58 \%)$. It can be observed that reaction times about 60 minutes allow low inorganic content and high TDS in the black liquor. However, reaction times about 30 minutes resulted in a more effective degree of delignification on the raw material.

\section{Lignin Characterization of Residual Liquor}

The representative FTIR spectra of the different lignins obtained are shown in the Fig. 4. In these spectra the following structures can be identified: O-H stretching (3400 $\left.\mathrm{cm}^{-1}\right), \mathrm{C}-\mathrm{H}$ stretching in methyl and methylene groups $\left(2978,2836 \mathrm{~cm}^{-1}\right), \mathrm{C}-\mathrm{O}$ stretching in conjugated ketone with aromatic ring $\left(1647 \mathrm{~cm}^{-1}\right)$, aromatic skeletal vibrations (1558, 1520, 1458, $\left.1419 \mathrm{~cm}^{-1}\right), \mathrm{C}-\mathrm{H}$ asymmetric deformations $\left(1377 \mathrm{~cm}^{-1}\right)$, syringyl ring breathing with $\mathrm{C}-\mathrm{O}$ stretching $\left(1328 \mathrm{~cm}^{-1}\right)$, guaiacyl ring breathing with $\mathrm{C}-\mathrm{O}$ stretching $\left(1233 \mathrm{~cm}^{-1}\right)$, and deforming in $\mathrm{C}-\mathrm{H}$ and $\mathrm{O}-\mathrm{H}$ groups $\left(1202 \mathrm{~cm}^{-1}\right)$. Others structures that can be found are: C-O and C-C stretching vibrations $\left(1077 \mathrm{~cm}^{-1}\right)$ (D3), C-H in-plane deformation in guaiacyl groups $\left(1139 \mathrm{~cm}^{-1}\right)$ (D4), and $\mathrm{C}-\mathrm{O}$ vibrations $\left(1081 \mathrm{~cm}^{-1}\right)$ (D4). Hemicelluloses indicative bands were found in all samples analyzed: glycosidic bond vibrations $\left(1030 \mathrm{~cm}^{-1}\right)$ and $\beta$-glucosidic bond vibration between polysaccharides (916$\left.836 \mathrm{~cm}^{-1}\right)$. Based on the FTIR spectra, lignins are contaminated with polysaccharides fractions. However, TGA analyses were carried out to determine the degree of contamination that the lignins show. 
Table 4. Black Liquor Characterization

\begin{tabular}{|c|c|c|c|c|c|c|c|c|c|c|}
\hline \multirow{2}{*}{$\begin{array}{l}\text { BLACK } \\
\text { LIQUOR }\end{array}$} & \multirow{2}{*}{$\mathrm{pH}$} & \multirow{2}{*}{$\begin{array}{l}\text { Density } \\
(\mathrm{g} / \mathrm{mL})\end{array}$} & \multicolumn{2}{|c|}{ TDS $^{a}$} & \multicolumn{2}{|c|}{$\mathrm{MI}^{\mathrm{b}}$} & \multicolumn{2}{|c|}{$\mathrm{MO}^{\mathrm{C}}$} & \multicolumn{2}{|c|}{ Lignin } \\
\hline & & & $(\%)$ & $(\mathrm{g} / \mathrm{mL})$ & $(\%)$ & $(\mathrm{g} / \mathrm{mL})$ & (\%) & $(\mathrm{g} / \mathrm{mL})$ & $(\mathrm{g} / \mathrm{mL})$ & (\%) \\
\hline $\begin{array}{c}\mathrm{D} 1 \\
(170,60,65)\end{array}$ & 9.41 & 9.9686 & 5.84 & 0.5821 & 1.44 & 0.1432 & 4.40 & 0.4389 & 3.98E-03 & 0.040 \\
\hline $\begin{array}{c}\mathrm{D} 2 \\
(185,90,80)\end{array}$ & 9.47 & 9.9741 & 5.53 & 0.5513 & 1.48 & 0.1474 & 4.05 & 0.4039 & 4.29E-03 & 0.043 \\
\hline $\begin{array}{c}\text { D3 } \\
(155,90,80)\end{array}$ & 9.50 & 10.1258 & 8.12 & 0.8223 & 1.97 & 0.1998 & 6.15 & 0.6224 & 4.28E-03 & 0.042 \\
\hline $\begin{array}{c}\text { D4 } \\
(185,90,50)\end{array}$ & 9.23 & 10.0984 & 4.60 & 0.4641 & 2.22 & 0.2241 & 2.38 & 0.2400 & 3.61E-03 & 0.036 \\
\hline $\begin{array}{c}\text { D5 } \\
(155,90,50)\end{array}$ & 9.13 & 10.0520 & 3.42 & 0.3438 & 1.09 & 0.1093 & 2.33 & 0.2346 & 2.77E-03 & 0.028 \\
\hline $\begin{array}{c}\text { D6 } \\
(185,30,80)\end{array}$ & 9.49 & 10.0294 & 5.63 & 0.5650 & 1.52 & 0.1529 & 4.11 & 0.4122 & 3.67E-03 & 0.037 \\
\hline $\begin{array}{c}\mathrm{D} 7 \\
(155,30,80)\end{array}$ & 9.61 & 10.0624 & 7.58 & 0.7623 & 2.02 & 0.2028 & 5.56 & 0.5595 & 5.05E-03 & 0.050 \\
\hline $\begin{array}{c}\text { D8 } \\
(185,30,50)\end{array}$ & 9.29 & 10.0705 & 6.27 & 0.6317 & 1.32 & 0.1328 & 4.95 & 0.4988 & 7.00E-03 & 0.069 \\
\hline $\begin{array}{c}\text { D9 } \\
(155,30,50)\end{array}$ & 9.33 & 10.1103 & 5.78 & 0.5841 & 2.43 & 0.2453 & 3.35 & 0.3388 & $5.24 \mathrm{E}-03$ & 0.052 \\
\hline $\begin{array}{c}\mathrm{D} 10 \\
(170,90,65)\end{array}$ & 9.46 & 10.0832 & 6.25 & 0.6302 & 1.87 & 0.1886 & 4.38 & 0.4416 & 3.20E-03 & 0.032 \\
\hline $\begin{array}{c}\text { D11 } \\
(170,30,65)\end{array}$ & 9.39 & 10.0573 & 7.14 & 0.7179 & 1.82 & 0.1835 & 5.31 & 0.5344 & 3.49E-03 & 0.035 \\
\hline $\begin{array}{c}\mathrm{D} 12 \\
(170,60,80)\end{array}$ & 9.47 & 10.0765 & 5.58 & 0.5623 & 0.48 & 0.0166 & 5.42 & 0.5457 & 4.33E-03 & 0.043 \\
\hline $\begin{array}{c}\text { D13 } \\
(170,60,50)\end{array}$ & 9.32 & 10.0880 & 9.93 & 1.0017 & 0.65 & 0.0358 & 9.58 & 0.9659 & 3.92E-03 & 0.039 \\
\hline $\begin{array}{c}\text { D14 } \\
(185,60,65)\end{array}$ & 9.33 & 10.1199 & 6.21 & 0.6288 & 0.45 & 0.0182 & 6.03 & 0.6106 & 4.06E-03 & 0.040 \\
\hline $\begin{array}{c}\mathrm{D} 15 \\
(155,60,65) \\
\end{array}$ & 9.51 & 10.2126 & 7.72 & 0.7888 & 0.87 & 0.0465 & 7.27 & 0.7423 & 4.97E-03 & 0.049 \\
\hline
\end{tabular}

Thermal decomposition of lignins was determined by thermogravimetric analysis (TGA) under a nitrogen atmosphere. $\mathrm{DTG}_{\text {máx }}\left({ }^{\circ} \mathrm{C}\right)$ (weight loss rate) and residue (\%) are presented in Table 5. The results of analysis showed that the first weight loss in all lignins was due to the moisture of the samples; subsequently the second peak in all lignins could be ascribed to the degradation of polysaccharides (hemicelluloses) contamination (Tejado 2007) due to the extraction process followed. The last peak found in all lignins belonged to lignin degradation. The thermal degradation of lignin took place from 185 to $500{ }^{\circ} \mathrm{C}$, which can be understood due to the complex structure of lignin with phenolic hydroxyl, carbonyl groups and benzylic hydroxyl, which are connected by straight links (Domínguez et al. 2008). The residue obtained after thermal degradation was also related to the structural complexity of the lignin molecule and its degree of linkages. High residue percentages imply high thermal stability of the samples (Domínguez et al. 2008). However, high residue values also can indicate the presence of inorganic matter. For the analyzed samples it was found that lignins obtained from diethanolamine treatment showed a residue of 27 to $34 \%$. 


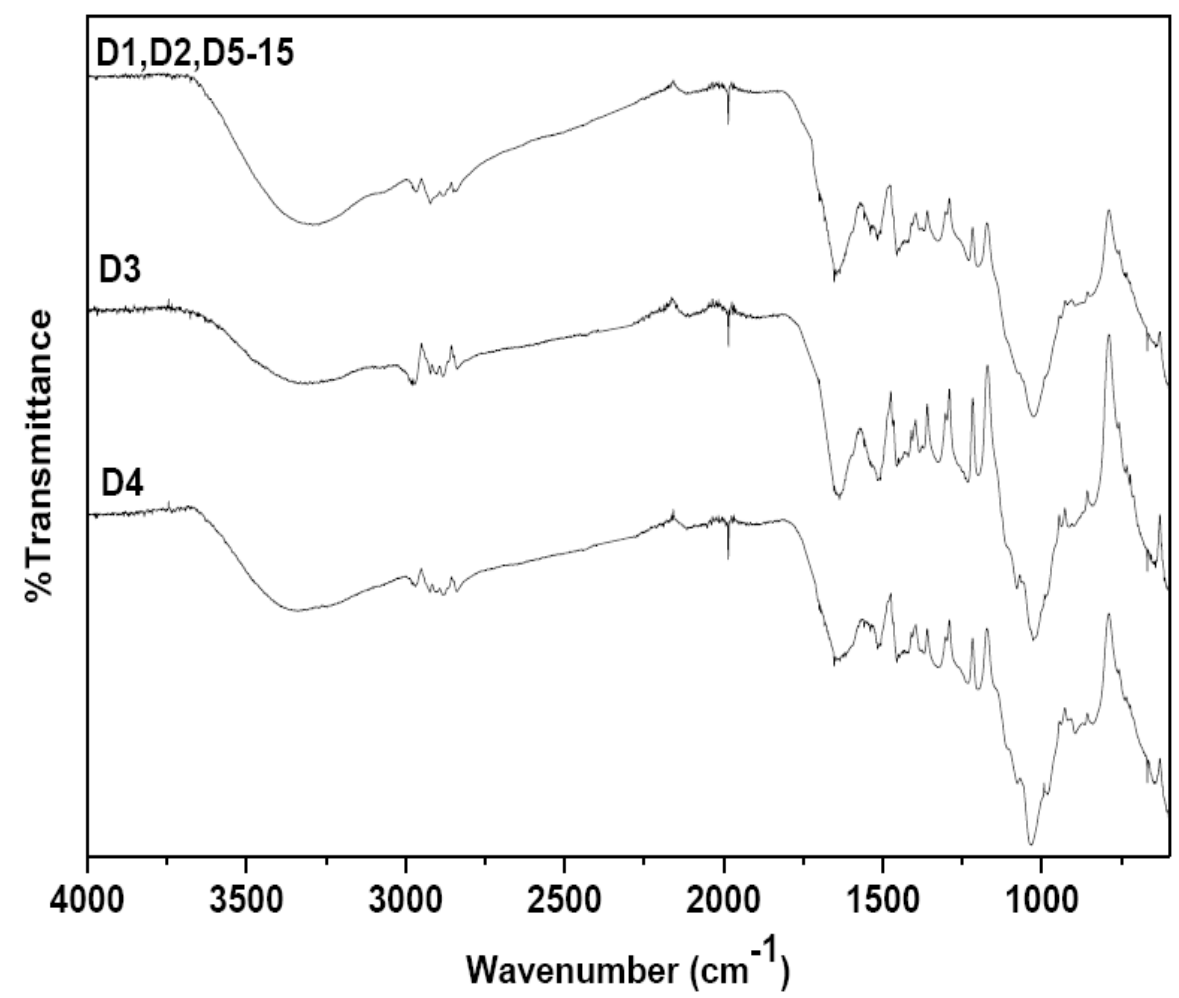

Figure 4. Representative FTIR spectra of Hesperaloe lignins recovered from diethanolamine black liquor

Table 5. Thermogravimetric Analysis (TGA) of Lignins

\begin{tabular}{ccccc} 
BLACK & \multicolumn{3}{c}{ DTG $_{\max }\left({ }^{\circ} \mathrm{C}\right)$} & \\
\cline { 2 - 4 } LIQUOR & Moisture & Hemicelluloses & Lignin & Residue $(\%)$ \\
\hline D1 $(170,60,65)$ & 82.91 & 248.56 & 376.93 & 30.48 \\
D2 $(185,90,80)$ & 90.57 & 260.00 & 346.17 & 33.92 \\
D3 $(155,90,80)$ & 94.63 & 261.00 & 374.00 & 32.88 \\
D4 $(185,90,50)$ & 90.43 & 243.07 & 385.56 & 33.72 \\
D5 $(155,90,50)$ & 78.43 & 247.08 & 375.67 & 31.46 \\
D6 $(185,30,80)$ & 72.00 & 252.17 & 338.33 & 30.75 \\
D7 $(155,30,80)$ & 79.83 & 228.67 & 330.50 & 29.34 \\
D8 $(185,30,50)$ & 84.17 & 241.51 & 381.79 & 29.92 \\
D9 $(155,30,50)$ & 72.00 & 228.67 & 330.50 & 26.91 \\
D10 $(170,90,65)$ & 79.83 & 260.00 & 338.33 & 29.51 \\
D11 $(170,30,65)$ & 78.13 & 220.76 & 354.00 & 29.74 \\
D12 $(170,60,80)$ & 77.25 & 249.49 & 375.22 & 24.79 \\
D13 $(170,60,50)$ & 83.60 & 243.64 & 377.07 & 30.50 \\
D14 $(185,60,65)$ & 87.67 & 244.33 & 338.33 & 32.07 \\
D15 $(155,60,65)$ & 118.13 & 275.11 & 377.22 & 31.84 \\
\hline
\end{tabular}




\section{Obtaining of Synthesis and Fuel Gases from Black Liquor}

The black liquor from pulping of raw material by the diethanolamine process was acidified in order to isolate lignin-rich fractions. Table 6 shows the results obtained at different $\mathrm{pH}$ values.

Table 6. Solid Fractions Extracted by Acidification of the Black Liquor Pulping and Overall Proportions of Gases Obtained their Pyrolysis and Gasification

\begin{tabular}{|c|c|c|c|c|}
\hline \multirow[t]{2}{*}{ Fraction } & \multirow[t]{2}{*}{$\begin{array}{l}\mathrm{pH} \text { for extraction } \\
\text { of solid fraction }\end{array}$} & \multirow{2}{*}{$\begin{array}{l}\text { Amounts of solid } \\
\text { extracted }(\mathrm{g}) \text { and } \\
\text { proportion with } \\
\text { respect to the sum } \\
\text { of solid fractions }\end{array}$} & \multicolumn{2}{|c|}{$\begin{array}{l}\text { Total amount of gases obtained } \\
\text { (\% with respect to the extracted } \\
\text { fraction) }\end{array}$} \\
\hline & & & Pyrolysis & Gasification \\
\hline 1 & 6 & $2.84(22.45 \%)$ & 77.9 & 87.5 \\
\hline 2 & 4 & $8.01(63.3 \%)$ & 75.1 & 97.3 \\
\hline 3 & 2 & $1.81(14.3 \%)$ & 74.1 & 99.6 \\
\hline
\end{tabular}

Diethanolamine cooking an amount of $500 \mathrm{~g}$ of $\mathrm{H}$. funifera provided pulp in a $55.1 \%$ yield. Based on the lignin contents of the raw material $(7.30 \%)$ and pulp $(6.66 \%)$, the cooking liquor should have contained $18.15 \mathrm{~g}$ of lignin. This amount, however, was much greater than the combination of the three individual fractions of Table 6: $12.66 \mathrm{~g}$. Since the solid fractions contain additional components such as hemicellulose and ash, only part of the solids in the liquors was lignin recovered by acidification.

As can be seen from Table 6, acidification of the diethanolamine pulping liquor at $\mathrm{pH} 4$ extracted the highest proportion of solid fraction (63.3\%). Therefore, using lower $\mathrm{pH}$ values to obtain other solid fractions may be counterproductive, as they will add little to the previous fraction and unnecessarily raise the cost of neutralizing the effluent (only $14.3 \%$ was extracted at $\mathrm{pH} 2$ ).

Thermal decomposition (until $527-627^{\circ} \mathrm{C}$ ) of the previous solid fractions (1 to 3 ) in an inert atmosphere $(\mathrm{He})$ and an oxidizing atmosphere $\left(9: 1 \mathrm{He} / \mathrm{O}_{2}\right)$ resulted in the weight losses shown in the Table 6 (column 4 and 5). These results indicate that in the pyrolysis, the weight loss of solid fractions considered was lower for the separated fractions to lower $\mathrm{pH}$ value. This suggests that pyrolysis of the solid fractions obtained at higher $\mathrm{pH}$ produced smaller amounts of carbonaceous residues and ash, and hence greater amounts of evolved gases (see fourth column in Table 6). In the case of gasification the results were otherwise: the solid fractions extracted at the higher $\mathrm{pH}$ values provided smaller amounts of gases (see last column in Table 6).

Samples of the different solid fractions (1 to 3 of Table 6) were pyrolysed and gasified in a horizontal tubular reactor, and the resulting gases were analysed by GC/FID and GC/TCD. The results are shown in Table 7. 
Table 7. Composition of Evolved Gases Generated by Pyrolysis and Gasification of the Solid Fractions

\begin{tabular}{llcccc}
\hline Process & Samples & $\mathrm{H}_{2}$ & \multicolumn{2}{c}{ Composition, g/100 $\mathrm{g}$ sample } & $\mathrm{CO}_{2}$ \\
\hline \multirow{4}{*}{ Pyrolysis } & Fraction 1 & 0.64 & 13.00 & 14.80 & 1.55 \\
& Fraction 2 & 0.74 & 10.50 & 12.80 & 2.37 \\
& Fraction 3 & 0.97 & 13.60 & 16.80 & 3.70 \\
& Fraction 1+2 & 0.71 & 11.16 & 13.33 & 2.16 \\
\hline \multirow{3}{*}{ Gasification } & Fraction 2 & 0.26 & 23.00 & 48.60 & 23.26 \\
& Fraction 1 & 4.92 & 20.40 & 38.40 & 14.01 \\
& Fraction 3 & 0.15 & 53.40 & 51.60 & 16.01 \\
& Fraction 1+2 & 1.48 & 22.32 & 45.94 & 20.84 \\
\hline
\end{tabular}

A comparison of the data in Table 7, reveals that pyrolysis of the solid fraction obtained by acidification of the diethanolamine cooking liquor at $\mathrm{pH} 6$ produced decreased amounts of $\mathrm{H}_{2}, \mathrm{CH}_{4}, \mathrm{CO}$, and $\mathrm{CO}_{2}$ relative to $\mathrm{pH} 2$; and decreased amounts of $\mathrm{H}_{2}$ and $\mathrm{CH}_{4}$ and increased amounts of $\mathrm{CO}$ and $\mathrm{CO}_{2}$ relative to $\mathrm{pH} 4$.

On the other hand, gasification of the fraction extracted at $\mathrm{pH} 6$ produced increased amounts of $\mathrm{H}_{2}$, but decreased amounts of $\mathrm{CH}_{4}, \mathrm{CO}$ and $\mathrm{CO}_{2}$, relative to $\mathrm{pH} 4$ and 2.

A comparison of the amounts of gases obtained by gasification and pyrolysis of the solid faction extracted from the diethanolamine cooking liquor at $\mathrm{pH} 4$ (the most abundant fraction) reveals that gasification produced less $\mathrm{H}_{2}$ but more $\mathrm{CO}, \mathrm{CO}_{2}$, and $\mathrm{CH}_{4}$ than pyrolysis.

Gasification provided very small amounts of $\mathrm{H}_{2}$ with all fractions, except that extracted from diethanolamine liquor at $\mathrm{pH}$ 6. The fraction extracted at the lower $\mathrm{pH}$ value gave greater amounts of $\mathrm{CO}$ and $\mathrm{CO}_{2}$. Finally, the largest amount of $\mathrm{CH}_{4}$ was obtained from the diethanolamine liquor extracted at the intermediate $\mathrm{pH}$.

Based upon the above, the fraction separated from the cooking liquor at $\mathrm{pH} 2$ can be considered more appropriate, both for production of synthesis gas $\left(\mathrm{H}_{2}+\mathrm{CO}\right)$ and for fuel gas $\left(\mathrm{CO}+\mathrm{H}_{2}+\mathrm{CH}_{4}\right)$.

For practical purposes the cooking liquor should be directly acidified to $\mathrm{pH} 4$, thereby achieving an overall fraction that would be sum of fractions 1 and 2 of Table 6 . Table 7 shows the overall composition of this fraction (fraction $1+2$ ), where it can be calculated that the amounts of synthesis gas and fuel gas produced during the pyrolysis process would correspond to 11.87 and $14.03 \mathrm{~g} / 100$ sample, respectively; for the case of the gasification process these quantities reach 23.80 and $44.64 \mathrm{~g} / 100 \mathrm{~g}$ sample, respectively. 


\section{CONCLUSIONS}

1. The Hesperaloe funifera plant, due to the values obtained for its content of cellulose is a suitable raw material for the production of cellulosic pulp.

2. Neural fuzzy models tested provided a good fit of experimental data for the calculation of all dependent variables (with errors less than $12 \%$ ), except for tear index and brightness.

3. The pulping process influences several properties of the obtained lignins. Hesperaloe lignins precipitated from black liquor of diethanolamine process showed high contamination due to presence of polysaccharides (hemicelluloses). For this reason, a diethanolamine process with hesperaloe is not suitable to obtain lignins with specific applications; rather, the black liquor could be concentrated and used for its calorific value.

4. A comparison of the amounts of synthesis gases $\left(\mathrm{H}_{2}+\mathrm{CO}\right)$ and fuel gases $\left(\mathrm{H}_{2}+\right.$ $\mathrm{CO}+\mathrm{CH}_{4}$ ) generated by pyrolysis and gasification of the solid fractions obtained by acidifying the pulping liquors revealed that the best results were those for the diethanolamine black liquor extracted at $\mathrm{pH} 2$, but as the most abundant solid fraction is obtained by direct acidification to $\mathrm{pH} \mathrm{4}$, this should be the fraction used to produce synthesis gas and fuel gas.

\section{ACKNOWLEDGMENTS}

The authors would like to thank the Spanish Ministry of Science and Innovation (CTQ 2006-10329/PPQ and CTQ2007-65074-C02), the University of the Basque Country (2008 post-doctoral researcher's specialization program) and to Ecopapel, S.L. (Écija, Seville, Spain) for their support.

\section{REFERENCES CITED}

Baumlin, S., Broust, F., Bazer-Bachi, F., Bourdeaux, T., Herbinet, O., Touize-Ndiaye, F., Ferrer, M., and Lede, J. (2006). "Production of hydrogen by lignins phase pyrolysis," Int. J. Hydrogen Energy 31(15), 2179-2192.

Bunarov, A. U., and Mazza, G. (2008). "Lignin in straw of herbaceous crops (review)," Ind. Crops Prod. 28, 237-259.

Cateto, C. A., Barreiro, M. F., and Rodrigues, A. E. (2008a). "Monitoring of lignin-based polyurethane synthesis by FTIR-ATR," Ind. Crops Prod. 27, 168-174.

Cateto, C. A., Barreiro, M. F., Rodrigues, A. E., Brochier-Salon, M. C., Thielemans, W., and Belgacem, M. N. (2008b). "Lignins as macromonomers for polyurethane synthesis: A comparative study on hydroxyl group determination," J. Appl. Polym. Sci. 109 (5), 3008-3017.

Conesa, J. A., Font, R., Fullana, A., Martín-Gullón, I., Aracil, I., Gálvez, A., Moltó, J., and Gómez-Rico, M. F. (2009). "Comparison between the pollution emission in the pyrolysis and combustion of different wastes," J. Anal. Appl Pyrol, 84, 95-112. 
Cordeiro, N., Belgacem, M. N., Torres, I. C., and Moura, J. C. V. P. (2004). "Chemical composition and pulping of banana pseudo-stems," Ind Crops Prod. 19, 147-154.

Domínguez, J. C., Oliet, M., Alonso, M. V., Gilarranz, M. A., and Rodríguez, F. (2008). "Thermal stability and pyrolysis kinetics of organosolv lignins obtained from Eucalyptus globulus," Ind. Crops Prod. 27, 150-156.

Fairbank, M., and Detrick, R. (2000). "Hesperaloe funifera. An excellent reinforcement fiber for mechanical paper grades," Tappi J. 83(11), 1-9.

Fengel, D., and Wegener, G. (eds.) (1989). Wood: Chemistry, Ultrastructure, Reactions, Walter de Gruyter, Berlin and New York.

Furusawa, T., Sato, T., Sugito, H., Miura, Y., Ishiyama, Y., Sato, M., Itoh, N., and Suzuki, N. (2007). "Hydrogen production from the gasification of lignin with nickel catalysts in supercritical water," Int. J. Hydrogen Energy 32, 6, 699-704.

García Hortal, J. A. (2007). "Fibras papeleras,” Editorial UPC. Barcelona. Spain

Gargulak, J. D., and Lebo, S. E. (2000). In: Lignin: Historical, Biological, and Materials Perspectives, Glasser, W. G., Northey, R. A., and Schultz, T. P. (eds.), American Chemical Society, Washington, 305-320.

González, M., Tejado, A., Blanco, M., Mondragon, I., and Labidi, J. (2009).

"Agricultural palm oil tree residues as raw material for cellulose, lignin and hemicelluloses production by ethylene glycol pulping process," Chem. Eng. J. 148, 106-114.

Guillot Ortíz, D., and Van der Meer, P. (2006). "El género Hesperaloe Engelm. en la Península Ibérica e Islas Baleares,” Botanica Complutensis 30, 137-145.

http://faostat.fao.org Accessed March 2010.

http://aspapel.es Accessed March 2010.

http://ili-lignin.com Accessed June 2010

Jang, J. S. R. (1993). “ANFIS: Adaptive-network-based fuzzy inference system,” IEEE Transactions on Systems, Man and Cybernetics 23(3), 665-685.

Jiménez, L., Pérez, A., de la Torre, M. J., Rodríguez, A., and Angulo, V. (2008). "Ethyleneglycol pulp from tagasaste," Bioresource Technol. 99, 2170-2176.

López, F., Alfaro, A., Jiménez, L., and Rodríguez, A. (2006). “Alcohols as organic solvents for the manufacture of cellulose pulps," Afinidad 63(523), 174-182.

Lora, J. H., and Glasser, W. G. (2002). "Recent industrial applications of lignin: A sustainable alternative to non-renewable materials," J. Polym. Environ. 10(1-2), 3948.

Mani, T., Muruga, P., and Mahinpey, N. (2009). "Determination of distributed activation energy model kinetic parameters using simulated annealing optimization method for nonisothermal pyrolysis of lignin," Ind. Eng. Chem. Res. 48(3), 1464-1467.

McLaughlin, S. P. (2000). "Properties of paper made from fibers of Hesperaloe funifera (Agavaceae)," Econ. Bot. 54(2), 192-196.

Montgomery, D. C. (1991). Design and Analysis of Experiments, Grupo Editorial Iberoamericana, Mexico, p. 303. México.

Murugan, O., Mahinpey, N., Johnson, K., and Wilson, M. (2008). "Kinetics of pyrolysis of lignin using thermogravimetric and differential scanning calorimetry methods," Energ Fuel 22(4), 2720-2724. 
Osada, M., Hiyoshi, N., Sato, O., Arai, K., and Shirai, M. (2007). "Reaction pathway for catalytic gasification of lignin in presence of sulfur in suprecritical water," Energy Fuel 21(4), 1854-1858.

Park, Y., Doherty, W. O. S., and Halley, P. J. (2008). “Developing lignin-based resin coatings and composites," Ind. Crops Prod. 27, 163-167.

Perlack, R. D., Wright, L. L., Turhollow, A. F., Graham, R. L., Stokes, B. J., and Erbach, D. C. U. S. (2005). "Biomass as Feedstock for a bioenergy and bioproducts industry: the technical feasibility of a billion-ton annual supply," U.S. Department of Energy.

Ragauskas, A. J., Nagy, M., Kim, D. H., Eckert, C. A., Hallet, J. P., and Liotta, C. L. (2006). "From wood to fuels: integrating biofuels and pulp production," Ind. Biotechnol. 2(1), 55-65.

Rodríguez, A., and Jiménez, L. (2008). "Pulping with organic solvents other than alcohols," Afinidad 65(535), 188-196.

Rodríguez, A., Moral, A., Serrano, L., Labidi, J., and Jiménez, L. (2008a). "Rice straw pulp obtained by using various methods," Bioresource Technol. 99, 2881-2886.

Rodríguez, A., Serrano, L., Moral, A., Pérez, A., and Jiménez, L. (2008b). "Use of highboiling organic solvents for pulping oil palm empty fruit bunches," Bioresource Technol. 99, 1743-1749.

Tejado, A. (2007). "Modificación de matrices novolacadas por uso de compuestos naturales. Caracterización físico-química de ligninas y estudio del curado y de las propiedades de resinas lignofenólicas," Doctoral thesis, University of the Basque Country, Spain.

van Heiningen, A. (2006). "Converting a kraft pulp mill into an integrated forest products biorefinery," Pulp Pap. Can. 107(6), 38-43.

Wise, L. E., Murphy, M. and D’Adieco, A. (1946). “Chlorite holocellulose its fractionation and beating on summative wood analysis and on studies on the hemicellulose," Paper Trade J. 122(2), 35.

Wong, A., and McLaughlin, S. P. (1999). "Papermaking pulp from Hesperaloe species, an arid-zone native plant from northern Mexico," Proc $4^{\text {th }}$ Biomass Conference of the Americas, Oakland, California, USA.

Wong, A., and McLaughlin, S. P. (2000). "Alkaline sulphite pulping of Hesperaloe, an arid-zone native fiber plant from northern Mexico," Proc Tappi Pulping Conference, Boston.

Works, G. A. (1989). 'Neural network basics,” Proceeding AUTOFACT'89, 29, 1-9.

Yamaguchi, A., Hiyoshi, N., Sato, O., Osada, M., and Shirai, M. (2008). "Lignin gasification over supported ruthenium trivalent slats in supercritical water," Energy Fuel 22(3), 1485-1492.

Yamaguchi, A., Hiyoshi, N., Sato, O., Osada, M., and Shirai, M. (2009). "Hydrogen production from woody biomass over supported metal catalysts in supercritical water," Catalysts Today 146(1-2), 192-195.

Zadeh, L. A. (1965). "Fuzzy sets,” Information and Control 8, 338-353.

Article submitted: September 15, 2010; Peer review completed: October 10, 2010; Revised version received: October 22, 2010; Accepted: October 31, 2010; Published: November 3, 2010. 